\title{
Criminometric Analysis: Testing the Deterrence Hypothesis in Sabah
}

\author{
Siti Nur Zahara Hamzah \\ Swinburne University of Technology, Sarawak Campus \\ Jalan Simpang 3, 93350 Kuching \\ Sarawak, Malaysia \\ shamzah@swinburne.edu.my
}

\author{
Evan Lau \\ Faculty of Economics and Business \\ Universiti Malaysia Sarawak \\ 94300 Kota Samarahan, Sarawak \\ lphevan@,feb.unimas.my
}

\begin{abstract}
This paper empirically estimates disaggregated crime categories for Sabah from 1968 to 2006. The criminometric analysis incorporated in a within sample analysis of cointegration and error correction framework and the beyond sample analysis using the decompositions of variance. Our findings suggest that any support for the deterrence hypothesis is sensitive to the inclusion of prison or courts related variables. In the long run we find that only robbery is exogenous in all crime model tested however, the beyond sample estimation proves that in longer time period of approximately 50 years the post-sample dynamic VDC imply that a substantial portion of the variance of the forecast error of these crime are explained by their explanatory variables.
\end{abstract}

Keywords-component; econometric, crime, Sabah, cointegration, VECM, VDC.

\section{INTRODUCTION}

Crime is a by-product of development [1] in which societies are becoming more materialistic and anomistic. Anomie can be referred to as "normless" state where individuals' goals are more important than the means adopted to attain them, and it is likely to be a feature of periods of rapid economic or social change. References [2] pointed out that under those conditions where anomie is prevalent; all types of crime may be expected to rise in the society including non-pecuniary crimes like rape and murder [3]. Since growth and development are concerned with economists and policy makers, so do crime. Crime or the non-compliance attitude of individuals can be viewed as negative externality with destructive power.

References [3] while explaining Malaysian public expenditure on the criminal-justice system highlighted that, growth in crime rates would sooner or later become a threat to the society and feeling of insecurity may prevail and it may take a somewhat long time to become obvious or to be noticed. Elsewhere in the literature, Malaysia became important country for analysis of crime in criminology [4], blue water crime [5], policing [6], [7] and [8] and economics [9], [10], [11], [12], [13] and [14]. All studies, at best, provide mixture finding for crime in Malaysia hence, consensus on the support for economics of crime theory had never been achieved.

References [15] contends that the possibility of bias due to omitted variable can never be denied however, it is impossible to capture all variables that are said to be the influence in increasing crime rates (see [16] and [17] for examples). Omitted variable bias are also been accused as the reasons for conflicting results obtained in the literature of economics of crime. According to [18], conviction rate and time served are theoretically important but often neglected in economics of crime analysis. This can generates omitted variable bias if in reality those neglected variables are indeed correlated with arrest rate.

This study intend to make a humble attempt in finding relationship between crime and economic determinants while at the same time proving the effectiveness of existing law and enforcement strategy in Sabah. Sabah's fluid cultural, social and economic boundaries with both Indonesia and the Philippines renders the role of national identities, citizenship and formal economic networks less important than the informal transnational networks that facilitates the flow of commodities and humans across boundaries. This often left undetected by the Malaysian/Sabahan state apparatus. These undetected activities are said to be root cause for increasing Sabah's crime rates in recent years which event called for a Memorandum of Understanding (MoU) to be signed between the Sabah National Unity and Integration Department (NUID) and districts' police in order to reduce crime rates in the district level. The rest of the papers is constructed as follows with section 2 provides the discussion on the literature review, section 3 illustrates the methodology used for the analysis, section 4 present the results and section 5 conclude the overall findings.

\section{ECONOMETRIC METHODOLOGY}

\section{A. Theoretical Framework}

Following [19] and its extension in [20], this paper estimates following models of economics of crime for deterrence and determinants analysis in Sabah:

$C_{r}=\alpha+\beta_{1} Y_{r}+\beta_{2} U_{r}+\beta_{3} C D_{r}+\beta I M P_{r}+\beta R E C_{r}+\mu$

where $C_{r}$ refers to the crime rate; $Y_{r}$ is the GDP that represents the legitimate income level; $U_{r}$ is the unemployment rate which is the proxy for gains from illegitimate activities and time to allocate into illegitimate activities; $C D_{r}$ is the number of cases 